protrusions on a vertical surface in water, $J$. Electronic Packaging 111, 121-128 (1989).

12. W. Elenbaas, Heat dissipation of parallel plates by free convection, Physica 9, 1-28 (1942).

13. E. M. Sparrow and L. F. A. Azevedo, Vertical-channel natural convection spanning between the fully developed limit and the single-plate boundary-layer limit, $J$. Heat Transfer 28, 1847-1857 (1985).

14. J. R. Bodia and J. F. Osterle, The development of free convection between heated vertical plates, J. Heat Transfer 84, 40-44 (1961).

15. R. A. Wirtz and R. J. Stutzman, Experiments on free convection between vertical plates with symmetric heating, J. Heat Transfer 104, 501-507 (1982).

16. G. C. Vliet, Natural convection local heat transfer on constant heat flux inclined surfaces, Int. J. Heat Mass Transfer 18, 511-517 (1969).

\title{
The combined effects of fog formation and Stefan flow on nickel and iron evaporation into helium
}

\author{
H. J. H. Brouwers $\dagger$ \\ Akzo Research Laboratories Arnhem, Fibers Division. Department of Mechanical Engineering, \\ Velperweg 76, 6824 BM Arnhem, The Netherlands
}

(Received II November 1991)

\section{INTRODUCTION}

ONE FIELD of problems involving the combined eflects of Stefan flow and fog formation is the evaporation of molten metals into much colder gases. The enhancement of induction-heated iron/nickel alloys evaporation into stagnant helium by fog formation has been described theoretically by Turkdogan [1], Rosner [2] and Hills and Szekely [3, 4], and investigated experimentally by Turkdogan and Mills [5]. In some experiments Toop [6] also found that metal evaporation occurs at rates considerably higher than those predicted by conventional mass transfer correlations.

The former two investigators treated supersaturation in the gas in terms of a 'critical supersaturation model' (CSM). In both papers the assumption was made that the temperature field in the stagnant film is undisturbed by fog formation and therefore remains a linear function of the coordinate. This representation of the process is allowed only ir. cases where the vapour is extremely dilute.

On the basis of a combined analysis of the energy and diffusion equations, coupled with the basic saturation condition (thus excluding supersaturation), Hills and Szekely [4] obtained good agreement with the experimental data of Turkdogan and Mills [5]. In all the discussed analyses of iron/nickel alloys evaporation, however, Stefan flow in the considered transferring film was not taken into account. despite the fact that Rusner [2] and Hills and Szekely [4] mentioned that Stefan flow cannot be neglected for temperatures above $2000^{\circ} \mathrm{C}$.

To provide a rather more rigorous representation of the process, the procedure suggested by Brouwers [7] for the combined effects of Stefan flow and the condensation mechanism is applied in this note. First, the existence and magnitude of a fog layer is determined. Next, the mass transfer correction factor that reckons with both fog iormation and Stefan flow is applied to the process. This correction factor followed from the asymptotic approximation solution of the energy and diffusion cquations, coupled by the saturation condition, of a stagnant film iincluding fog formation and Stefan flow (referred to as 'induced velocity'). Furthermore, the compound correction factor of Brouwers [8] is also employed to assess said effects. This correction factor vriginates from a multiplication of the classical film model correction factor for Stefan flow by the fog film model correction factor for fog only.

†Present address: Deparment of Civil Engineering, Twente University, P.O. Box 217, 7500 AE Enschede, The Netherlands.

\section{FORMULATION}

A stagnant helium film next to an iron and or nickel cvaporating wall is considered. At the liquid surface $(y=0)$ the iron/nickel (or vapour) mass fraction is $c_{\mathrm{i}}$ and the temperature $t_{\mathrm{i}}$. At a distance $\delta_{c}$, the bulk vapour mass fraction $c_{\mathrm{b}}$ is attained, and at a distance $\delta$, the bulk temperature $t_{\mathrm{b}}$. As both the vapour pressures and moiecular masses of iron and nickel are very similar, the approximation of Hills and Szekely [4] is adopted by considering the evaporation of pure nickel only.

The first step is to examine whether fog is formed in part or all of the film. To this end, the slope condition of Brouwers [7] is utilized to verify if supersaturation takes place

$$
\left.\frac{\mathrm{d} F}{\mathrm{~d} t}\right|_{l_{\mathrm{i}}}>L e_{\mathrm{v}} \frac{c_{\mathrm{j}}-1}{l_{\mathrm{b}}-t_{\mathrm{i}}}\left[\exp \left\{\frac{\delta_{\mathrm{t}}}{L e_{\mathrm{v}} \delta_{c}} \ln \left(\frac{\mathrm{l}-c_{\mathrm{b}}}{\mathrm{I}-c_{\mathrm{i}}}\right)\right\}-1\right]
$$

where interface vapour fraction $c_{\mathrm{i}}=F\left(t_{\mathrm{i}}\right)$. The saturation line $F(t)$ lollows from the thermally perfect gas law and Gibbs-Dalton's law

$$
F(t)=\frac{M_{\mathrm{v}} P_{\mathrm{v}}(t)}{M_{\mathrm{v}} P_{\mathrm{v}}(t)+M_{\mathrm{n}}\left(P_{\mathrm{to1}}-P_{\mathrm{v}}(t)\right)} .
$$

The total absolute pressure $P_{\text {tot }}$ of the nickel-helium mixture considered amounts to $1 \mathrm{~atm}(=1.01325 \mathrm{bar})$ and the bulk properties concerned are : $t_{\mathrm{b}}=77^{\circ} \mathrm{C}, c_{\mathrm{b}}=0$. The molecular mass $M_{\mathrm{v}}$ of nickel and $M_{\mathrm{n}}$ of helium are 58.71 and 4.00 $\mathrm{kg} \mathrm{kmol}^{-1}$, respectively. The liquid saturation pressure of nickel, $\ln \left(P_{\mathrm{v}} /[\mathrm{bar}]\right)=32.41-51578 / T /[\mathrm{K}]-2.01 \ln (T /[\mathrm{K}])$, taken from Smithells [9], is applicable since $t_{\mathrm{i}} \geqslant 1500^{\circ} \mathrm{C}$, which is well above the melting point of nickel $\left(\cong 1455^{\circ} \mathrm{C}\right)$.

In view of the fact that $L e$ is close to unity (typically $L e=2.2$, see Rosner [2], this value is used throughout this note) and the absence of externally imposed flow, the approximation $\delta_{t}=\delta_{c}$ is applicable. The specific heat of the mixture follows from the expression for perfect monatomic gases:

$$
c_{p}=\frac{5 R}{2 M}
$$

where $R$ is the universal gas constant, $R=8316.94 \mathrm{~J} \mathrm{kmol}^{-1}$ $\mathrm{K}^{-1}$. The mean molecular mass $M$ is evaluated with the help of the arithmetic mean of the mole fractions of nickel and helium at the interface and bulk. The specific heat $c_{p, v}$ of nickel readily follows from equation (3) when $M=M_{v}$ is substituted. With $L e, c_{p}$ and $c_{p, v}$ determined, $L e_{\mathrm{v}}$ is now specified. For the entire $t_{\mathrm{i}}$ range examined, $1500^{\circ} \mathrm{C} \leqslant t_{\mathrm{i}}$ 


\section{NOMENCLATURE}

c nickel mass fraction

$c_{p} \quad$ specific heat $\left[\mathrm{J} \mathrm{kg}^{-1} \mathrm{~K}^{-1}\right]$

$F$ saturation vapour mass fraction

$G$ relation between $c$ and $t$ in superheated region

$H_{\text {lat }}$ latent heat of condensation [ $\left.\mathrm{J} \mathrm{kg}^{-1}\right]$

Le Lewis number, $k / \rho c_{p} \mathbb{D}$

Le, modified Lewis number, $k / \rho c_{r, s} \mathbb{D}$

$M \quad$ mass of $1 \mathrm{kmol}$ of substance $[\mathrm{kg}]$

$P$ pressure [bar]

$R \quad$ universal gas constant $\left[\mathrm{J} \mathrm{kmol}{ }^{\prime \prime} \mathrm{K}^{-1}\right]$

$T$ absolute temperature [K]

I temperature [ C]

I. coordinate normal to wall [m].
Greek symbols

$\delta_{\text {. }} \quad$ diffusional film thickness $[\mathrm{m}]$

$\delta$, thermal film thickness [III]

$\Theta_{c .1}$ mass transfer correction factor.

Subscripts

a border of saturated and superheated region

b bulk

i interface

Il non-condensables

tot total

$\checkmark$ vapour. $\leqslant 2500 \mathrm{C}$, equation (1) revealed that supersaturation is assured.

The next step is to determine the boundary of the saturated region $\left(0 \leqslant y \leqslant \delta_{u}\right)$ and superheated region $\left(\delta_{a} \leqslant y \leqslant \delta_{b}=\delta_{r}\right)$ in the film with the help of the langency condition of ref. [7]:

$$
\left.\frac{\mathrm{d} F}{\mathrm{~d} t}\right|_{t_{a}}=\left.\frac{\mathrm{d} G}{\mathrm{~d} t}\right|_{t_{a}}=L e_{\mathrm{v}} \frac{c_{a}-\mathrm{I}}{t_{\mathrm{h}}-t_{a}}\left[\exp \left\{\frac{1}{L e_{\mathrm{v}}} \cdot \ln \left(\frac{1-c_{\mathrm{b}}}{1-c_{a}}\right)\right\}-1\right]
$$

where $t_{a}$ and $c_{a}$ denote the temperature and vapour mass fraction at the boundary of both regions $\left(y=\delta_{u}\right)$. Equation (4) is based on the requirement that $t, c, \mathrm{~d} t / \mathrm{d} l$ and $\mathrm{d} c / \mathrm{d} y$ are continuous at $y=\delta_{a}$. Applying this equation yields as boundary of saturated and superheated region $t_{a}=79.5 \mathrm{C}$ and $c_{a}=F\left(t_{a}\right) \cong 0$. Since $t_{\mathrm{i}} \geqslant 1500 \mathrm{C}$ the conclusion can be drawn that $\left(t_{a}, c_{a}\right) \cong\left(t_{b}, c_{b}\right)$ and hence $\delta_{a} / \delta_{c}=\delta_{u} / \delta_{t} \cong 1:$ so that an entire fog film is obtained. This feature has in fact been implicilly assumed by Hills and Szekely [4], which now appears to be correct a posteriori. Furthermore, Brouwers [101 proved that a superheated region in the saturated region is not possible. so that an entirely fogging film is ensured.

Just as Hills and Szekely [4], the saturation condition has been assumed to prevail in the supersaturated film, the vapour mass fraction being expressed by equation (2). In the vicinity of the wall the fog droplets are indeed in a liquid state since the temperature exceeds the melting temperature there. By Turkdogan [ 1 ] it was furthermore discussed that the droplets remain also in a liquid state at temperatures of $300-400^{\circ} \mathrm{C}$ below the melting temperature. As the coupled heat and mass transfer is governed in the vicinity of the surface, and the difference between liquid and solid vapour pressure is modest for $t<1100 \mathrm{C}$, the liquid vapour pressure can therefore be taken to prevail in the entire film.

The asymptotic mass transfer correction factor for the effect of injection and fog formation ('equation (43)' and 'equation (44)' from Brouwers [7]) yields :

$$
\Theta_{c, f}=\left.\frac{\left(\frac{c_{p}}{c_{p, v}} L e-1\right)\left(t_{\mathrm{h}}-t_{\mathrm{i}}\right)+\ln \left(1-c_{\mathrm{i}}\right)\left(\frac{H_{\mathrm{lut}}}{c_{p, v}}+\frac{\left(t_{\mathrm{b}}-t_{\mathrm{i}}\right)\left(1-c_{\mathrm{i}}\right)}{.-c_{\mathrm{i}}}\right)}{-L e \frac{c_{p}}{c_{p, v}} c_{\mathrm{i}}-\left.\frac{H_{\mathrm{lat}}}{c_{p, v}} \frac{1}{1-c_{\mathrm{i}}} \frac{\mathrm{d} F}{\mathrm{~d} t}\right|_{t_{i}} c_{\mathrm{i}}} \frac{\mathrm{d} F}{\mathrm{~d} t}\right|_{t_{\mathrm{i}}}
$$

For $c_{\mathrm{i}} \ll 1$ equation (5) is approximated by

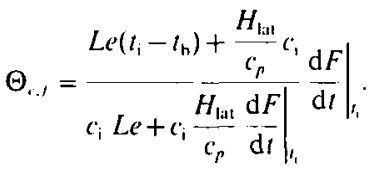

When $L e=1$ is substituted this correction factor clearly corresponds with $S h / N u(N u \cong 3)$ of Hills and Szekely [4] ("equation (14)", in which the second bracket of the numerator should be placed after the last term). For $c_{i} \mathrm{~d} F / \mathrm{d} t_{i} \cong 0$ equation (6) further reduces to

$$
\Theta_{i, f}=\left.\begin{array}{cc}
t_{\mathrm{i}}-t_{\mathrm{b}} \mathrm{d} F \\
c_{\mathrm{i}} & \mathrm{d} t
\end{array}\right|_{t_{1}}
$$

which corresponds to $i_{\min }^{\prime \prime} / I_{\min }^{\prime \prime}$ (equation (17)' where $\mathscr{L}^{\prime}=$ 1) of Rosner [2] when $c_{\mathrm{i}}^{-1} \mathrm{~d} F / \mathrm{d} t_{\mathrm{i}} \equiv F^{-1}\left(t_{\mathrm{i}}\right) \mathrm{d} F / \mathrm{d} t_{\mathrm{i}} \cong$ $P_{v}^{-1}\left(T_{\mathrm{i}}\right) \times \mathrm{d} P_{v} / \mathrm{d} T_{\mathrm{i}}$ is substituted.

The effect of Stefan flow and fog formation on the evaporation process can also be described with the compound fog film mode] correction factor of Brouwers [8]. Applying this correction factor yields :

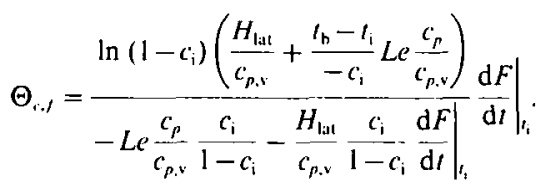

One can verify that equations (5) and (8) become identical for $c_{\mathrm{j}}$ tending to zero. Note that to compute the compound correction factor it is, unlike the asymptotic correction factor, no longer necessary to determine the boundary of superheated and saturated regions.
The approximate solution can be applied as both $H_{k a 1} / c_{p, v}$

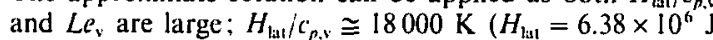
$\mathrm{kg}^{-1}$, see Smithells [9]) and $17<L e c_{p} / c_{p, \mathrm{v}} \equiv L e_{\mathrm{v}}<33\left(c_{p}\right.$ depends on $t_{\mathrm{i}}$ ). By Brouwers [7] it was demonstrated that for moderate temperatures and vapour mass fractions, here $t_{\mathrm{i}} \leqslant 2500^{\circ} \mathrm{C}$ and $c_{\mathrm{i}} \leqslant 0.66$, the accuracy of the asymptotic solution improves with larger $H_{\mathrm{lat}} / c_{n, \mathrm{v}}$ and $L e_{\mathrm{v}}$.

\section{RESULTS}

Both the resulting asymptotic and the compound correction factors for evaporation are now calculated for interface temperatures ranging from 1500 up to $2500^{\circ} \mathrm{C}$, as drawn in Fig. 1. In this figure also the experimental data of Turkdogan and Mills [5] and the theoretical CSM predictions of 


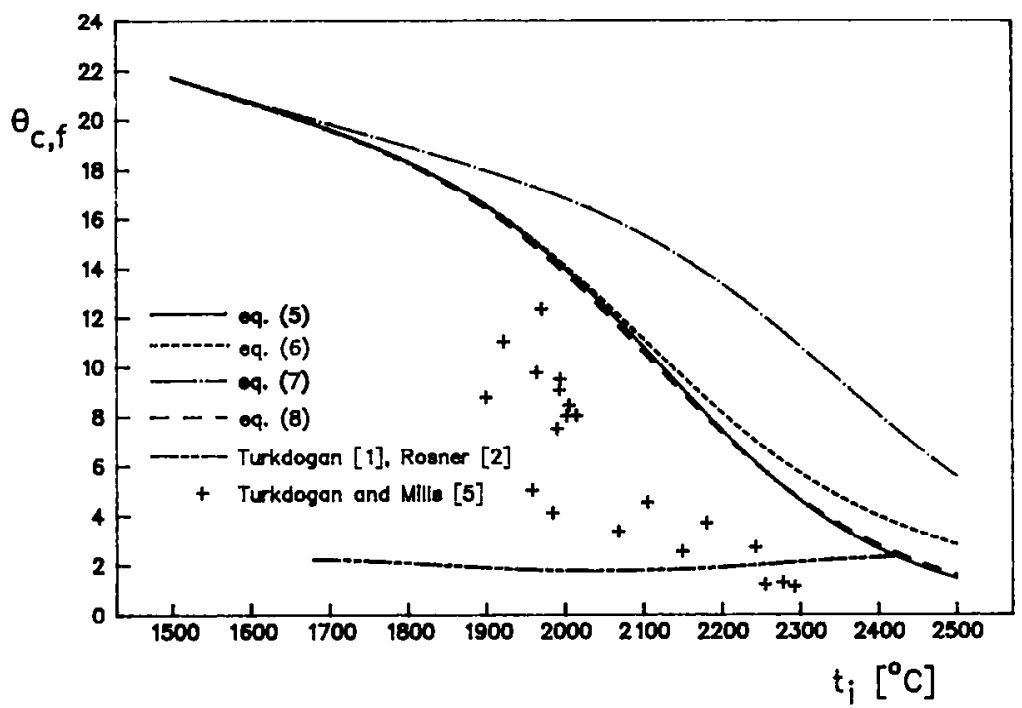

Fig. 1. Mass transfer correction factors for nickel evaporation into helium for various interface temperatures.

Turkdogan [1] and Rosner [2]. taken from Hills and Szekely [4], are depicted.

The figure shows the enhancement of the evaporation rates, $\Theta_{f,}>1$, by fog formation in the film. Equation (7) clearly overestimates this enhancement because it does not account for the effect of liberated latent heat in the fog layer on the temperature profile in the film. The main difference between equations (5) and (8) on the one hand and equation (6) on the other is caused by the allowance made in the former equations for the reducing effect of injection on evaporation. The difference increases at increasing $t_{i}$ and $c_{i}$, as might be expected.

For $t_{\mathrm{i}}=2500 \mathrm{C}$ injection already causes a reduction of about $50 \%$, which will rise dramatically when the boiling temperature of nickel ( $\cong 2915 \mathrm{C}$ ) is approached (that is to say, $c_{\mathrm{i}}$ approaches unity). A comparison with the depicted experimental data reveals that (owing to the assumption of the saturation condition) equations (5) and (8) still overestimate $\Theta$. . If the effect of supersaturation in the mixture were taken into account, $\Theta_{c,}$, would be further reduced.

Figure $I$ reveals that the predictions of asymptotic and compound fog film model will correspond. This can be understood from the fact that both the numerator and the denominator of equations (5) and (8) are dominated by the $H_{1,1} / c_{p, v}$ terms, which appear in the same form in both equations. Note that a similar agreement between both film models has also been found by Brouwers [8] for air watervapour mixtures.

\section{CONCLUSIONS}

In this note the fog film models of refs. [7, 8] have been utilized to predict the evaporation of nickel/iron alloys into helium, in particular its enhancement by fog formation and reduction by Stefan flow. The computations revealed that the asymptotic approximation solution and the compound fog film model closely correspond to one another.

Furthermore, by comparing the film model results with those of previous researchers, it was demonstrated that at higher interface temperatures and vapour fractions the substantial enhancement is significantly reduced by the injection effect. Accordingly, the used expressions of refs. [7, 8] are found to be more appropriate to situations where the vapour mass fraction is no longer negligible and, hence, an appreciable Stefan flow is encountered. The investigation further suggested that a combined consideration of Stelan flow and possible supersaturation would result in an even beller representation of the system examined.

Acknowledgements-The author wants to thank the management of Akzo Rescarch Laboratorics Arnhem for their permission to publish this paper and Messrs H. P. Korstanje and G. Vegt for their support. He also wants to express his gratitude to Prof: A. K. Chesters of Eindhoven University of Technology for his stimulating discussion on the subject.

\section{REFERENCES}

1. E. T. Turkdogan, The theory of enhancement of diffusion-limited vaporization rates by a convection-condensation process. Part I. Theoretical. Trans. Metall. Soc. A.I.M.E. 230, 740-750 (1964).

2. D. E. Rosner. Enhancement of diffusion-limited vaporization rates by condensation within the thermal boundary layer, Int. J. Heat Mass Tiansfer 10, 1267-1279 (1967).

3. A. W. D. Hills and J. Szekely. Notes on vaporization into much colder surroundings, Chem. Engng Sci. 17, 79-81 (1964)

4. A. W. D. Hills and J. Szekely. A note on the enhancement of the diffusion limited vaporization rates by condensation within the thernal boundary layer, $l m t . J$. Heat Mass Transfer 12, 111-114 (1969).

5. E. T. Turkdogan and K. C. Mills, The theory of enhancement of diffusion-limited vaporization rates by a convection-condensation process. Part 2. Experimental, Trans. Metall. Soc. A.I.M.E. 230, 750-753 (1964).

6. G. W. Toop, Reactions between gases and levitated metals, Ph.D. Thesis, University of London (1964).

7. H. J. H. Brouwers. Film models for transport phenomena with fog formation: the fog film model, $\mathrm{Int}$. J. Heat Mass Transfer 35, 13-28 (1992).

8. H. J. H. Brouwers, A film model for heat and mass transfer with fog formation, Chem. Engng Sci. 47, 30233036 (1992).

9. C. J. Smithells, Metals Reference Book (5th Edn). Butterworths, London (1976).

10. H. J. H. Brouwers, An analysis of multiple superheated and saturated regions in a stagnant binary film, $I n t . J$. Heat Mass Transfer 35, 1838-1841 (1992). 